\section{“De quem é esse bebê?": desafios para o direito à maternidade de mulheres em situação de rua}

\author{
"Whose baby is this?": challenges for homeless \\ women's right to motherhood
}

“¿De quién es ese bebé?": desafíos para el
derecho a la maternidad de mujeres sin techo

\author{
Gilney Costa Santos 1 \\ Tatiana Wargas de Faria Baptista 1 \\ Patrícia Constantino 1
}

\section{Resumo}

As experiências de mulheres gestantes em situação de rua colocam na arena do debate público tensões entre garantias individuais e limites às ações do Estado. Este artigo analisa a produção científica sobre o tema, a fim de reconhecer os argumentos biomédicos, jurídicos e sociais que sustentam os posicionamentos neste debate. A partir de uma revisão integrativa, em bases de abrangência nacional e internacional, foram analisados 21 estudos e identificados quatro enunciados: Riscos à saúde da mulher e do feto/criança; Discursos sobre o prénatal; Direitos de mulheres e de fetos/crianças; e Os sentidos sobre maternidade. Conclui-se que a experiência de maternidade dessas mulheres é extremamente complexa, não apenas pela situação de rua, mas por todo contexto, marcado por relações desiguais de classe, raça e gênero. Nos cenários nacional e internacional, sobressai o discurso de proteção e cuidado ao bebê/feto, em detrimento das mulheres gestantes. A criminalização dessas maternidades tem sido uma tendência global em que a expansão dos direitos "fetais/infantis" significa a retração dos direitos das mulheres. Esse modo de operar não produz e não incentiva que as mulheres busquem os serviços sociais e de saúde, mas o contrário. Torna-se um imperativo ético e humanitário pensar outros modos de cuidar, ancorados na perspectiva dos direitos humanos, para que a assistência ao feto/criança não se traduza em violência às mulheres.

Mulheres; Gênero; Maternidade; Pessoas em Situação de Rua; Direitos Humanos

\author{
Correspondência \\ G. C. Santos \\ Departamento de Estudos sobre Violência e Saúde Jorge Careli, \\ Escola Nacional de Saúde Pública Sergio Arouca, \\ Fundação Oswaldo Cruz. \\ Av. Brasil 4036, sala 700, Rio de Janeiro, RJ 21040-361, Brasil. \\ gilney.costa@yahoo.com.br \\ 1 Escola Nacional de Saúde Pública Sergio Arouca, Fundação \\ Oswaldo Cruz, Rio de Janeiro, Brasil.
}




\section{Introdução}

Este artigo tem como objeto de reflexão a maternidade de mulheres em situação de rua. Com base em uma revisão integrativa 1 , faz-se uma incursão nos discursos científicos, analisando como se apresentam e se articulam os enunciados biomédicos, jurídicos e sociais sobre este tema.

A ideia de mulher e sua associação com a maternidade é uma construção social 2. No Ocidente, a figura da mulher remete ao sagrado e à pureza, como aquela que cuida de seus filhos e da casa. Já a mulher em situação de rua tem sido associada à prostituição, ao perigo e à criminalidade 3 . Abordar as experiências de maternidade dessas mulheres tensiona essas construções e coloca em discussão os limites entre a liberdade individual e a ação do Estado.

No cenário internacional, este tema tem ganhado destaque, desde os anos 1950, em função do número crescente de casos judicializados e, em torno deles, os debates sobre direitos sexuais e reprodutivos dessas mulheres, bem como a legitimidade dos "direitos fetais" ${ }^{4}$. Uma agenda ainda hoje não equacionada que se expressa no cotidiano dos serviços de saúde, do judiciário e da assistência em forma de dilemas em torno ora da defesa dos direitos das mulheres ora das crianças/bebês/feto.

No Brasil, a discussão sobre a situação de vida e saúde das mulheres e de seus bebês, no contexto da rua, ocupou o debate social, político e jurídico, especialmente a partir de 2012, fortemente associado ao uso de drogas. O tema alcançou a mídia, sugerindo uma relação direta entre o uso de drogas e a situação de rua, (re)produzida pelo discurso moral da "dependência química", em que a droga seria a causa da passagem à vida na rua 5 .

Esse discurso, contudo, não é isento de interesses e comumente se mostra equivocado: nem todas as pessoas que estão em situação de rua usam drogas, assim como, os motivos pelos quais a "vida na rua" acontece tem um amplo espectro de justificativas que varia desde gerações que já nascem nas ruas até mesmo aquelas que por circunstâncias a vida nas ruas se torna uma realidade/alternativa.

Ademais, as notícias sensacionalistas 5 que sustentam a produção do discurso moral 6 apagam o contexto de vulnerabilidade social das mulheres, tornando-se uma relevante estratégia de manutenção do status quo e de criminalização dessas mulheres, consideradas inaptas para o exercício da maternidade. Assim, tais narrativas normalizam a "guerra aos pobres", travestida oficialmente de "guerra às drogas", servindo para induzir e justificar as estratégias proibicionistas frente às propostas da redução de danos 6,7,8.

Para Santos et al. 9 , a situação dessas mulheres e de seus bebês denuncia um mal-estar social ancorado nas históricas e desiguais relações de gênero, classe e raça que incidem sobre corpos específicos: mulheres, em sua grande maioria pretas e pobres, cuja história de vida é marcada por violências estruturais e institucionais. Trata-se de mulheres que vivem em um profundo contexto de desamparo e desproteção social, desafiando normas instituídas sobre o que é ser mulher e mãe, provocando respostas do Estado 3 .

Nas últimas décadas, essas respostas implicaram a estruturação de uma rede de cuidado integrada entre atenção básica e saúde mental, com a expansão dos Centros de Atenção Psicossocial e a implantação das equipes de Consultórios na Rua. Em contrapartida, foram adotadas medidas para o enfrentamento do uso de drogas, em especial o crack 10, que reforçaram o olhar higienista sobre a população de rua, configurando um cenário de disputa em torno dos modelos de cuidado, no qual recursos públicos do financiamento dos serviços do Sistema Único de Saúde (SUS) foram alocados no setor privado, sobretudo no financiamento das Comunidades Terapêuticas 11.

Para as mulheres, as medidas proibicionistas têm incidido diretamente sobre seus direitos reprodutivos. Em 2014, a Promotoria da Infância e da Juventude de Belo Horizonte (Minas Gerais) publicou duas Normativas 12,13 destinadas às maternidades e unidades básicas de saúde, recomendando a comunicação imediata às autoridades dos partos de mulheres usuárias de drogas e, ou, em situação de rua. Dois anos mais tarde, uma Portaria 14 foi editada, desta vez pela Vara Cível da Infância e da Juventude daquela capital, estabelecendo o prazo de 48 horas, a partir do nascimento do bebê, para a comunicação dos partos às autoridades, sujeitando profissionais de saúde a punições, caso descumprissem as determinações.

As práticas de separação mãe/bebê implementadas nesses últimos anos - como em Belo Horizonte desde 201115 ou no Município do Rio de Janeiro a partir de 2013, quando 39 recém-nascidos foram afastados de suas mães porque se tratavam de mulheres em situação de rua usuárias de crack 3 
- remontam ao contexto das décadas de 1920 a 1980, quando milhares de crianças, filhos de pais diagnosticados com hanseníase, foram separadas e encaminhadas aos chamados preventórios, enquanto seus pais eram isolados em "leprosários" 16.

As práticas proibicionistas - aí incluídas a internação, laqueadura e a separação compulsórias entre as mulheres e seus bebês -, inicialmente restritas a algumas capitais brasileiras, se tornaram objeto de denúncias de movimentos sociais ligados aos Direitos Humanos, como os movimentos feministas e as universidades. Esses denunciavam que mulheres em situação de rua e, ou, com histórico de uso de drogas tinham seus filhos sequestrados ainda nas maternidades e encaminhados para a adoção, pela Justiça, à revelia das mães, mesmo quando estas manifestavam o desejo pela criança e buscavam meios para garantir a sua criação.

As denúncias explicitavam que esse modo de operar é parcial, pois focava no uso da droga sem considerar a história e o contexto de vida dessas mulheres; seletivo, uma vez que as decisões incidiam, em sua grande maioria, em corpos de mulheres pretas e pobres em situação de rua, "capturadas" ao acessarem serviços públicos da assistência social ou da saúde; e moral, haja vista que quase nunca essas mesmas decisões consideravam os homens, genitores dos bebês, como parte do processo reprodutivo 17.

Em 2016, uma Nota Técnica do Ministério da Saúde e do Ministério do Desenvolvimento Social e Combate à Fome 18 reiterou que a vulnerabilidade dos pais e o uso de drogas não são motivos para a separação familiar, representando uma resposta ao Ministério Público de Belo Horizonte 9. Em 2018, a revista Saúde em Redes publicou um número temático reunindo artigos de pesquisadoras, movimentos sociais e defensorias públicas, somando-se aos esforços de denúncia, sinalizando que no "estado civilizatório que o neoliberalismo vem produzindo, (...) há vidas que valem mais que outras, e muitas (...) que não valem a pena (...) deixa-se morrer, ou mesmo mata-se" 19 (p. 7).

No mesmo ano, a Rede Unida realizou o XIII Congresso Internacional (http://www.redeunida. org.br/pt-br/evento/5/), expondo centenas de meias em um varal, cada uma representando um bebê retirado compulsoriamente de suas mães. Esse varal exibia trechos de depoimentos das mulheres a respeito do desejo de maternar, seguido da pergunta: "De quem é esse bebê?".

A denúncia chamava atenção para o caráter eugênico da ação, que ao advogar em defesa dos direitos do mais vulnerável, perpetuava a estrutura de opressão, uma vez que não envidava esforços práticos com vistas a encontrar soluções efetivas para o problema dessas mulheres - pretas, pobres, em situação de rua e, ou, usuárias de drogas - e dos seus bebês.

Essas questões mobilizaram a realização deste estudo, que reconhece que as respostas institucionais à situação de vida e saúde dessas mulheres e de seus bebês requerem a produção de saberes sobre o tema. Olhar para as produções científicas sobre essa temática é provocar um debate acerca das práticas e políticas de saúde.

\section{Metodologia}

Este é um estudo de revisão integrativa da literatura científica sobre a maternidade de mulheres em situação de rua. A revisão integrativa abrange um conjunto de técnicas para recuperar, mapear, selecionar, avaliar e produzir análises críticas a respeito da produção de conhecimento sobre um objeto/ questão de pesquisa 1 .

Na construção do panorama de uma temática, a revisão integrativa não forma um todo homogêneo, como sugere o termo "integrativa"; por vezes, a revisão integrativa explicita (e é o desejável) as contradições, os apagamentos, possibilitando identificar razões pelas quais um tema ou uma agenda de pesquisa ascende.

A opção por esse método justifica-se pelo reconhecimento das potencialidades de análise sobre a forma como são retratadas nos estudos a maternidade/maternagem das mulheres em situação de rua. São duas perguntas-chave: (i) Quais enunciados sustentam a produção desses textos?; e (ii) Como saberes biomédicos, jurídicos e socioantropológicos atravessam a produção social e política dessas maternidades?

O levantamento bibliográfico ocorreu em junho de 2019, com duas estratégias de busca usando-se descritores nas línguas portuguesa e inglesa nas seguintes bases: Biblioteca Virtual em Saúde (BVS), Scopus, Web of Science e SciELO. A primeira estratégia consistiu na combinação simples dos descri- 
tores "mulheres, maternidade e rua" com o objetivo de maior alcance (Figura 1). A segunda consistiu numa estratégia mais específica incorporando um número maior de descritores e duas outras bases nacionais: o Portal Brasileiro de Publicações Científicas em Acesso Aberto (Oasis) e o Catálogo de Teses e Dissertações da Coordenção de Aperfeiçoamento de Pessoal de Nível Superior (CAPES).

Os estudos recuperados foram organizados usando-se o software Mendeley (https://www.men deley.com), facilitando a limpeza da base e checagem de duplicidades. Foram consideradas as publicações em português, inglês ou espanhol que estivessem disponíveis e acessíveis. Uma primeira identificação dos estudos foi realizada baseando-se nos títulos e validada por dois pares ad hoc. Em seguida, foram excluídos os textos sem versão completa. Depois da leitura dos resumos foram mantidos os trabalhos que de alguma forma estavam relacionados à temática da maternidade de mulheres em situação de rua e excluídos os estudos clínicos, protocolos de rotina dos serviços e os específicos de avaliação de serviços, sem uma discussão propriamente sobre as mulheres e a situação de rua.

Os trabalhos selecionados deram origem a uma matriz de dados organizada com base nas seguintes informações: título; autores; filiação; objetivo; tipo de estudo; métodos/metodologia; participantes; principais resultados; área de conhecimento; idioma; ano; local da publicação; e fomento. Em seguida, foi realizada uma leitura exaustiva dos estudos buscando reconhecer os núcleos de sentidos 20 . Na perspectiva das práticas discursivas, os núcleos de sentido dizem respeito à compreensão da linguagem (escrita, falada, imagética e corporal) como práticas sociais em ação 20, que expressam condições de possibilidades históricas e políticas nas quais estão ancoradas a produção dos discursos.

A análise foi realizada reconhecendo o saber biomédico, jurídico e socioantropológico como discursos e lugares de fala que ofertam modos diferentes de olhar para o tema, em permanente tensionamento, inclusive no interior de cada um deles, posto que não produzem enunciados únicos. Ao observá-los questionamos: Como esses saberes e discursos se conectam? Como se transformam? Quais as disputas em jogo? Quais as interfaces entre os enunciados produzidos?

\section{Resultados e discussões}

A ideia de mulher é uma construção social que na modernidade ganhou contornos nítidos ao ser associada à ideologia de um amor instintivo à prole e uma devoção virtuosa ao lar 21. Sobre os corpos de mulheres operam regras e padrões de normalidade, tendo a ciência um importante papel na construção de práticas e saberes que incidem sobre estes corpos. A mulher vista como sinônimo de mãe reflete esse ideal construído e toda vez que algo coloca esse padrão em questão há tensionamentos. As experiências de maternidade das mulheres em situação de rua colocam em xeque o estabilishment, provocando debates e análises tanto no meio social como no acadêmico.

A produção científica identificada nesta revisão integrativa (Quadro 1) expressa diferentes racionalidades e modos de entendimento sobre as experiências de maternidade dessas mulheres. O córpus de análise foi constituído por 21 estudos, com base nos quais quatro enunciados foram identificados: (I) Riscos à saúde da mulher e do feto/criança: predominante no contexto das discussões internacionais, este enunciado está ancorado na perspectiva dos estudos biomédicos sobre fatores de risco argumentando que o contexto da rua, por si só, já representaria risco para a ocorrência de efeitos adversos à gestação dessas mulheres. Esse argumento é disputado pelos estudos socioculturais, que incorporam uma perspectiva macroestrutural na produção desses riscos, questionando o peso do contexto social e político ou o estilo de vida;

(II) Discursos sobre o pré-natal: tanto no contexto internacional quanto no brasileiro o pré-natal tem sido entendido como uma tecnologia de cuidado que favorece o controle e a mitigação dos fatores de risco que produzem efeitos adversos à gestação de mulheres em situação de rua. Aqui, prevalece o olhar das ciências sociais em saúde que alerta para o fato de que dispositivos jurídicos e normativos centrados na punição produzem desconfiança, levam ao abandono e à recusa das mulheres em procurar os serviços de assistência social e saúde;

(III) Direitos de mulheres e de fetos/crianças: foram localizados apenas estudos internacionais. Este enunciado explicita as dubiedades entre a defesa dos direitos das mulheres e a defesa dos fetos/crianças. Mostram que enquanto os saberes jurídicos, mobilizados pelo Estado, partem do pressuposto de que as mulheres em situação de rua são inaptas para o exercício da maternidade, justificando a ideia 
Figura 1

Processo e etapas da busca bibliográfica.

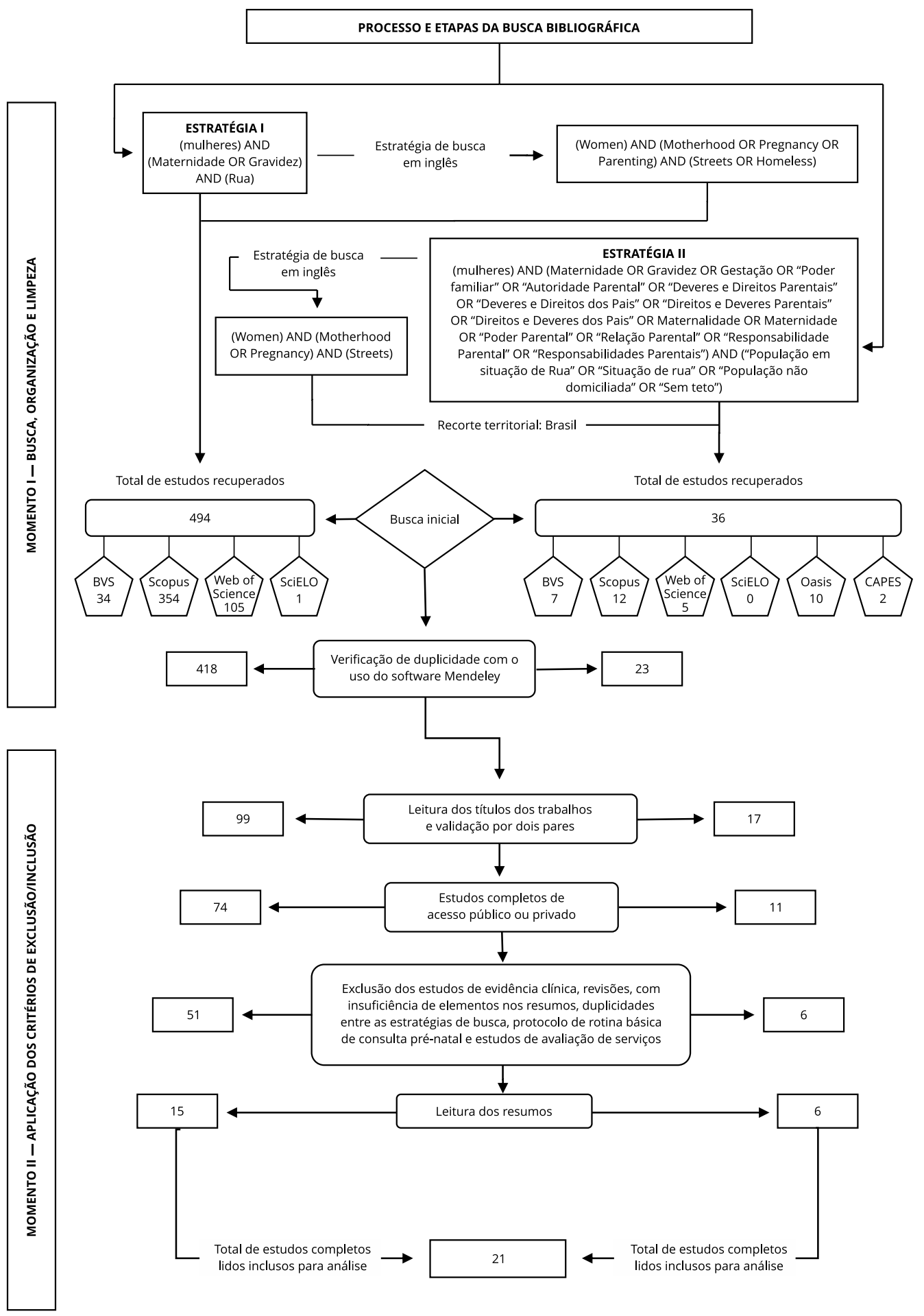

BVS: Biblioteca Virtual em Saúde; CAPES: Coordenação de Aperfeiçoamento de Pessoal de Nível Superior; Oasis: Portal Brasileiro de Publicações Científicas em Acesso Aberto.

Fonte: elaboração própria. 
Quadro 1

Caracterização dos estudos publicados sobre mulheres em situação de rua com trajetória de uso de drogas.

\begin{tabular}{|c|c|c|c|}
\hline ENUNCIADO/ESTUDO (ANO) & PERIÓDICO & OBJETIVO & MÉTODOS \\
\hline \multicolumn{4}{|l|}{$\begin{array}{l}\text { Riscos à saúde da mulher e } \\
\text { do feto/criança }\end{array}$} \\
\hline Kassada et al. 22 (2013) & Acta Paulista de Enfermagem & $\begin{array}{l}\text { Determinar a prevalência do uso de drogas } \\
\text { de abuso por gestantes }\end{array}$ & Artigo quantitativo, transversal \\
\hline Sakamoto et al. 23 (2015) & Reprodução \& Climatério & $\begin{array}{c}\text { Avaliar o implante de etonogestrel em } \\
\text { mulheres da Cracolândia (região central da } \\
\text { cidade de São Paulo) }\end{array}$ & $\begin{array}{c}\text { Artigo empírico, quantitativo. } \\
\text { Mulheres moradoras da Cracolândia, } \\
\text { poliusuárias de drogas }\end{array}$ \\
\hline Rocha et al. 24 (2016) & Cadernos de Saúde Pública & $\begin{array}{l}\text { Analisar a prevalência e fatores associados } \\
\text { ao uso de drogas ilícitas durante a gestação }\end{array}$ & $\begin{array}{l}\text { Estudo quantitativo, transversal; } \\
\text { aninhado à coorte pré-natal de } \\
\text { mulheres gestantes usuárias de } \\
\text { drogas }\end{array}$ \\
\hline Gustavsson 25 (1992) & Social Work in Health Care & $\begin{array}{c}\text { Discutir criticamente as evidências } \\
\text { científicas encontradas em pesquisas } \\
\text { sobre incidência e consequência do uso } \\
\text { de substâncias químicas à saúde fetal e } \\
\text { materna }\end{array}$ & $\begin{array}{l}\text { Artigo de revisão teórica. Não há } \\
\text { referência aos métodos empregados } \\
\text { na produção do artigo }\end{array}$ \\
\hline Bassuk \& Winreb 26 (1993) & $\begin{array}{c}\text { American Journal of } \\
\text { Orthopsychiatry }\end{array}$ & $\begin{array}{c}\text { Explorar o impacto da falta de moradia } \\
\text { e seus efeitos adversos para mulheres } \\
\text { grávidas e seus bebês }\end{array}$ & Artigo empírico, qualitativo \\
\hline Bloom et al. 27 (2004) & $\begin{array}{c}\text { Journal of Obstetric, } \\
\text { Gynecologic, and Neonatal } \\
\text { Nursing }\end{array}$ & $\begin{array}{l}\text { Explorar e descrever as barreiras que } \\
\text { mulheres em situação de rua encontram } \\
\text { para acessar o pré-natal no nordeste da } \\
\text { Flórida (Estados Unidos) }\end{array}$ & $\begin{array}{l}\text { Artigo empírico, quantitativo; com } \\
\text { o uso de questionário aplicado às } \\
\text { mulheres em situação de rua }\end{array}$ \\
\hline Schempf \& Strobino 28 (2008) & Journal of Urban Health & $\begin{array}{c}\text { Discute em que medida os efeitos adversos } \\
\text { à saúde materno-infantil são consequências } \\
\text { do uso de drogas }\end{array}$ & $\begin{array}{l}\text { Artigo empírico, epidemiológico- } \\
\text { clínico. Autorrelato; prontuário e } \\
\text { exames toxicológicos da urina no } \\
\text { momento do parto. }\end{array}$ \\
\hline Leppo 29 (2012) & $\begin{array}{l}\text { International Journal on } \\
\text { Drug Policy }\end{array}$ & $\begin{array}{c}\text { Analisa as percepções das mulheres sobre } \\
\text { os riscos envolvidos no uso de drogas } \\
\text { durante o pré-natal }\end{array}$ & $\begin{array}{c}\text { Artigo empírico, qualitativo, } \\
\text { etnográfico }\end{array}$ \\
\hline \multicolumn{4}{|l|}{ Discursos sobre o pré-natal } \\
\hline Araújo et al. 31 (2017) & $\begin{array}{c}\text { Revista de Enfermagem UFPE } \\
\text { On Line }\end{array}$ & $\begin{array}{c}\text { Investigar como ocorrem os cuidados de } \\
\text { enfermagem }\end{array}$ & $\begin{array}{l}\text { Artigo empírico, qualitativo junto à } \\
\text { profissionais de Consultório na Rua }\end{array}$ \\
\hline Beal \& Redlener 32 (1995) & Seminars in Perinatology & $\begin{array}{c}\text { Discutir as implicações da realização do pré- } \\
\text { natal entre mulheres em situação de rua }\end{array}$ & Artigo empírico, qualitativo \\
\hline \multicolumn{4}{|l|}{$\begin{array}{l}\text { Direitos de mulheres e de } \\
\text { fetos/crianças }\end{array}$} \\
\hline Garcia 33 (1992) & Journal of Legal Medicine & $\begin{array}{l}\text { Analisa tensões entre os direitos de } \\
\text { mulheres/mães e os direitos fetais }\end{array}$ & $\begin{array}{c}\text { Artigo teórico/conceitual; } \\
\text { característica de ensaio }\end{array}$ \\
\hline Olsen 34 (2014) & Drug and Alcohol Review & $\begin{array}{c}\text { Discute as políticas de bem-estar infantil } \\
\text { que focam os pais que usam drogas }\end{array}$ & Artigo de natureza teórica \\
\hline Maher \& Curtis 35 (1992) & $\begin{array}{c}\text { Crime, Law, and Social } \\
\text { Change }\end{array}$ & $\begin{array}{l}\text { Problematiza a relação entre emancipação } \\
\text { feminina e aumento de delitos praticados } \\
\text { por mulheres }\end{array}$ & Artigo empírico, qualitativo \\
\hline Cohen 36 (2018) & Michigan Law Review & $\begin{array}{c}\text { Discute os efeitos dos dispositivos jurídicos- } \\
\text { normativos à saúde materno-infantil }\end{array}$ & Artigo de natureza teórica \\
\hline
\end{tabular}

(continua) 


\begin{tabular}{|c|c|c|c|}
\hline ENUNCIADO/ESTUDO (ANO) & PERIÓDICO & OBJETIVO & MÉTODOS \\
\hline Poland et al. 37 (1993) & $\begin{array}{l}\text { Drug and Alcohol } \\
\text { Dependence }\end{array}$ & $\begin{array}{l}\text { Discute, com base no ponto de vista das } \\
\text { mulheres usuárias de drogas grávidas, suas } \\
\text { atitudes em relação ao potencial efeito de } \\
\text { uma lei punitiva sobre o comportamento de } \\
\text { uso de substâncias durante a gravidez }\end{array}$ & Artigo empírico, qualitativo, entrevista \\
\hline Moss 38 (1991) & Women's Health Issues & $\begin{array}{l}\text { Analisa os efeitos dos marcos legais que } \\
\text { tratam sobre o uso de álcool e outras } \\
\text { drogas por mulheres grávidas }\end{array}$ & Artigo de natureza teórica \\
\hline \multicolumn{4}{|l|}{$\begin{array}{l}\text { Os sentidos sobre } \\
\text { maternidade }\end{array}$} \\
\hline Costa et al. 39 (2015) & Saúde e Sociedade & $\begin{array}{l}\text { Investiga o cotidiano de gestantes de rua } \\
\text { e sua relação com as políticas públicas na } \\
\text { cidade de Santos, litoral do Estado de São } \\
\text { Paulo }\end{array}$ & $\begin{array}{l}\text { Artigo empírico, qualitativo. Uso } \\
\text { de registro e estudo de narrativas } \\
\text { de memórias de vida de mulheres } \\
\text { gestantes em situação de rua }\end{array}$ \\
\hline Oliveira 40 (2015) & Tese de Doutorado & $\begin{array}{l}\text { Analisa o processo de naturalização e } \\
\text { responsabilização dos papéis socialmente } \\
\text { atribuídos à figura materna, no cuidado } \\
\text { material e emocional dos seus filhos }\end{array}$ & $\begin{array}{c}\text { Estudo de caso realizado com } \\
\text { mulheres mães de adolescentes e } \\
\text { jovens em situação de rua }\end{array}$ \\
\hline Almeida \& Quadros 41 (2016) & $\begin{array}{c}\text { Pesquisas e Práticas } \\
\text { Psicossociais }\end{array}$ & $\begin{array}{c}\text { Contar histórias e experiências no campo } \\
\text { de pesquisa junto a mulheres em situação } \\
\text { de rua e os modos como se relacionam com } \\
\text { a maternidade }\end{array}$ & $\begin{array}{l}\text { Artigo empírico, qualitativo, história } \\
\text { de vida }\end{array}$ \\
\hline McClelland \& Newell 42 (2008) & $\begin{array}{l}\text { Journal of Research in } \\
\text { Nursing }\end{array}$ & $\begin{array}{c}\text { Descreve as experiências da maternidade } \\
\text { de mulheres profissionais de sexo e } \\
\text { usuárias de drogas no contexto da rua }\end{array}$ & $\begin{array}{l}\text { Artigo empírico, qualitativo, grupo } \\
\text { focal }\end{array}$ \\
\hline King et al. 43 (2009) & Journal of Youth Studies & $\begin{array}{l}\text { Analisa narrativas de mulheres/mães sobre } \\
\text { os sentidos da maternidade }\end{array}$ & $\begin{array}{l}\text { Artigo empírico, qualitativo. Uso de } \\
\text { entrevista semiestruturada }\end{array}$ \\
\hline
\end{tabular}

Fonte: elaboração própria.

de que é preciso proteger fetos/crianças, as ciências sociais vão tensionar estes saberes denunciando a produção de estigmas, exclusão social, ruptura de vínculos afetivos e sociais, além de desestimular que as mulheres recorram aos serviços de saúde e assistência social;

(IV) Os sentidos sobre a maternidade: os estudos neste enunciado são majoritariamente nacionais e estão apoiados na perspectiva das ciências sociais. Discutem o desejo de maternar das mulheres em situação de rua como uma possibilidade de (re)construção de outros modos de caminhar pela vida. Esses estudos reconhecem que essas maternidades se distanciam do ideal, mas que há a possibilidade de exercê-las por meio de políticas públicas que amparem essas mulheres e seus bebês.

A organização desses textos com base na identificação desses enunciados considerou a centralidade das discussões presentes nos estudos. Trata-se, portanto, de uma organização didática, posto que as discussões dos textos se sobrepõem. Ressalte-se ainda que ao tratar os estudos, a discussão sobre drogas ganha importância e assume lugar de destaque na produção tanto nacional quanto internacional. Para além de unir textos e contextos tão diferentes, a "droga" aparece nos enunciados como dispositivo que justifica as estratégias de vigilância e intervenção sobre os corpos dessas mulheres e de seus descendentes. 
Riscos à saúde da mulher e do feto/criança

Em 8 dos 21 estudos foi identificado o enunciado dos riscos à saúde da mulher e do feto/criança. Três trabalhos problematizam o tema com base nas experiências brasileiras 22,23,24 e cinco nas do contexto internacional 25,26,27,28,29. Dispersos no tempo e no contexto, esses trabalhos compartilham a ideia de que os riscos atravessam a produção dessas maternidades, seja pela situação de rua, seja pelo uso de drogas.

Do ponto de vista conceitual, risco é uma medida probabilística que diz respeito às chances de um determinado agravo/evento acontecer. Em saúde pública, essa concepção inaugurou uma nova racionalidade no modo de organizar as práticas e serviços de saúde em que prevenir e controlar fatores de risco assumem a centralidade das ações 30 .

Nos estudos desta revisão, os enunciados relativos aos fatores de risco para a mulher e para o feto/criança aparecem em permanente tensionamento: seria o contexto de rua e o uso de drogas os fatores preponderantes para os desfechos adversos à saúde materno-infantil ou o contexto político e social, muitas vezes anterior à vida nas ruas e ao uso de drogas? 26,28. O que pesa mais para os desfechos adversos das gestações dessas mulheres: práticas de uso, tipo de substância, estilo de vida ou o contexto de pobreza, no qual o viver na rua se torna a expressão da precariedade? 26,29.

Esses tensionamentos estão ancorados em diferentes entendimentos sobre os riscos que vão desde os biomédicos, que partem do pressuposto de que o contexto da rua por si só já seria um risco à gestação que se soma ao uso de drogas, até os estudos socioculturais, que consideram que os fatores de risco são estruturais, portanto, relacionados ao contexto de precariedade da vida 25,26.

Do ponto de vista biomédico, os estudos enfatizam a relação causa/consequência e apontam como solução para uma maternidade "livre de riscos": o retorno ao domicílio e a abstinência do uso de drogas 22,23,24. Já a perspectiva dos estudos socioculturais traz os sentidos e percepções que as mulheres e profissionais de saúde constroem sobre os riscos e as condições de vida, trabalho e saúde 26,27,29.

Nos estudos de ênfase biomédica, há um esforço de localização dos possíveis desfechos adversos à gestação/nascimento: aborto 23 , problemas hemorrágicos, anemia, malformação fetal, prematuridade 27 , baixo peso ao nascer 28 e outros. O debate consiste em estabelecer relações entre condições de vida, hábitos e uso de substâncias, lícitas e ilícitas, e seus efeitos na saúde, em especial do feto/criança 24,28. Mas também em mostrar quando não existe nexo causal completamente estabelecido entre o uso de substâncias, a fase da gestão e a ocorrência de desfechos negativos 23,24,28.

Em alguns desses trabalhos 22,23, o discurso do risco está também associado à organização dos serviços, indicando que a situação de rua bem como o consumo de drogas ilícitas causam danos tanto individuais à saúde da mulher e do feto/criança quanto sociais, como, por exemplo, a expansão dos gastos dos sistemas de saúde, a sobrecarga na taxa de ocupação de leitos hospitalares e assistência social. Nesse contexto, há um estudo 25 que indica a atuação de uma cadeia industrial de testes toxicológicos na recomendação de testagem dessas mulheres e recém-nascidos (por meio do mecônio, cabelo materno e urina) como estratégia para controlar fatores de risco relacionados ao uso de drogas.

Outro estudo 23 compara os custos do parto e do cuidado com o recém-nascido de baixo e alto riscos com os custos-benefícios decorrentes de implantes de anticoncepcional subdérmico, com tempo de uso de três anos, contendo 68mg de etonogestrel, em uma população de 106 mulheres da região conhecida como "Cracolândia" de São Paulo. Para os autores 23, o investimento na prevenção de gestações não planejadas de mulheres em situação de rua e, ou, usuárias de drogas é a melhor e mais barata opção.

Noutra perspectiva, os estudos de abordagem sociocultural 26,27,29 entendem os fatores de risco como uma construção social regulada pelos lugares de fala de cada ator social. Assim, profissionais de saúde e mulheres em situação de rua com trajetória (ou não) de uso de drogas tendem a perceber riscos diferenciados 29.

Para Bassuk \& Weinreb 26, a distribuição dos riscos é marcadamente desigual. Segundo as autoras, os fatores de risco operam na fronteira das desigualdades estruturais, sendo sobre o corpo de mulheres negras e pobres que incidem de modo mais frequente e intenso as decisões de corte político, econômico e social que mantêm a reprodução histórica dos fatores de risco.

Coadunando com essa visão, Leppo 29 ressalta que o discurso biomédico que incide sobre as práticas de uso de drogas se volta ao corpo feminino na rua pela via da moralidade, em que a abstinência, 
além de representar um risco à saúde mental dessas mulheres, traz consigo um alto grau de exigência, pois muitas vezes para manter-se de "cara limpa" as mulheres precisam romper com vínculos e laços sociais significativos para elas.

Leppo 29 ressalta que, para as mulheres, a abstinência não resolve os riscos cotidianamente vivenciados em seu contexto social (pobreza, racismo, patriarcado, violências) e destaca que dentre suas preocupações está a possibilidade do bebê apresentar sintomas de abstinência e de sofrerem intervenções que levam a separação de seu bebê. Desse modo, as mulheres tendem a não buscar os serviços de assistência social e de saúde.

Os dados levantados por Leppo 29 rompem com narrativas que tendem a considerar as mulheres como negligentes em função da baixa adesão aos programas de pré-natal, e coadunam com os resultados apresentados por Bloom et al. ${ }^{27}$ para os quais as barreiras de acesso ao pré-natal constituem fatores de risco importantes para a ocorrência de eventos adversos à gestão/parto dessas mulheres.

\section{Discursos sobre o pré-natal}

O debate sobre o pré-natal dessas mulheres aparece em 2 dos 21 estudos 31,32. Embora tenham sido produzidos em distintos contextos, o primeiro brasileiro e o segundo de origem estadunidense, eles convergem para a ideia de que a maternidade dessas mulheres representa uma série de desafios para os profissionais e sistemas de saúde.

Há certo consenso entre esses autores 31,32 de que o pré-natal, quando bem manejado, isto é, em tempo oportuno para o diagnóstico precoce da gravidez, realização de testagem sorológica e acolhimento das demandas das mulheres, pode se tornar um dispositivo de cuidado capaz de controlar e reduzir riscos à saúde da gestante e do feto.

Para os autores 31,32, essas mulheres são marcadas por um amplo espectro de demandas que, comumente, extrapolam o setor saúde, inclusive durante o pré-natal. Esses desafios variam desde a emissão de documentos de identificação pessoal até a oferta de espaços de convivência mãe/bebê, em alguns casos, até mesmo familiar.

Os autores 31,32 também convergem a respeito da ideia de que a forma como os serviços se organizam para responder aos desafios colocados por essas mulheres pode ser crucial para o melhor desfecho da gestação, não apenas do ponto de vista das práticas biomédicas e assistenciais, mas da garantia de direitos das mulheres e de seus filhos.

Ao discutir a organização do pré-natal dessas mulheres, Araújo et al. 31 focam nas práticas assistenciais da consulta pré-natal de enfermagem, em serviço de Consultório na Rua. Já Beal \& Redlener 32 discutem as implicações do pré-natal para o controle e a redução dos fatores de riscos que produzem efeitos adversos às gestações dessas mulheres, como a pobreza, a desnutrição e as condições precárias de habitação.

Araújo et al. 31 (p. 4015-6) problematizam as práticas assistenciais considerando o lugar de fala das mulheres em situação de rua e advogam que "... a atenção pré-natal pode controlar os fatores de risco que trazem complicações à gestação, além de permitir a detecção e o tratamento oportuno de complicações, contribuindo para que o desfecho perinatal e maternal sejam favoráveis". Não obstante, alertam que "... número de consultas pré-natal, por maior que seja, não garante que a assistência seja adequada” 31 (p. 4106), assim o pré-natal tardiamente iniciado favorece a ocorrência de desfechos adversos ao nascimento (prematuridade, baixo peso ao nascer, óbito fetal e/ou materno). Para os autores 31 , pensar a (re)organização dos serviços de assistência materno-infantil, do ponto de vista dessas mulheres, implica reconhecer como elas se sentem nos serviços, quais os tratamentos são ofertados, os motivos que contribuem para que não procurem ou abandonem os serviços.

Os autores 31 também ressaltam que o ideário da Política Nacional de Humanização (PNH) favorece a perspectiva do lugar de fala e de escuta, deslocando o indicador abandono das explicações centradas nos estilos de vida para o entendimento de que não retornar aos serviços pode ser por desânimo, mas também, "por terem se sentido vítimas de preconceito na assistência institucional" 31 (p. 4106).

Desse modo, pensam o pré-natal não somente como a execução de exames laboratoriais, imunização e testes sorológicos, mas como momento de escuta 31 . Nessa perspectiva, a despeito da (re) organização das práticas assistenciais, apostam no pré-natal como um momento de encontros afetivos 
entre profissionais de saúde e “...gestantes de alto risco que devem receber atenção especial (...) à probabilidade de intoxicação aguda que procede ao momento do parto” 31 (p. 4106).

Outro ponto de convergência entre os dois estudos 31,32 é o reconhecimento de que essas gestações são produzidas em meio a vulnerabilidades sociais extremas e que organizar esse pré-natal exige uma produção de cuidado que extrapola o prescrito. Para Beal \& Redlener 32, existe um nível estrutural que dificulta o acesso dessas mulheres aos serviços de saúde e quando elas chegam não é só pensar a assistência. Para responder aos desafios colocados por essas mulheres é preciso que o pré-natal olhe não apenas para a questão da saúde, mas o contexto no qual essas maternidades são produzidas: a "desestruturação familiar, pouca capacidade de planejamento, abuso de substâncias" 32 (p. 308).

Trata-se, desse ponto de vista, de uma aposta política feita pelos autores 31,32 para a reorganização do cuidado em saúde, pois compreendem que é preciso reconhecer que as mulheres são diversas em suas necessidades e que os motivos que fazem com que mulheres/mães se encontrem em situação de rua são diferentes tanto quanto a forma como se relacionam com "a rua".

\section{Direitos de mulheres e de fetos/crianças}

O debate sobre os direitos das mulheres gestantes em situação de rua foi encontrado em 6 dos 21 estudos 33,34,35,36,37,38, em sua totalidade internacionais. Isso não significa que essas discussões não estejam acontecendo no Brasil, há produções nacionais importantes já sinalizadas, como o número temático da Rede Unida, que pautam esse debate, mas que não foram localizadas na revisão integrativa.

Os estudos 33,34,35,36,37,38 descrevem diferentes entendimentos jurídicos sobre a temática e como eles se expressam em práticas biomédicas e assistenciais no cotidiano dos serviços sociais e de saúde. Partem do reconhecimento de que há uma tensão entre os direitos das mulheres em situação de rua e os direitos fetais/infantis, com certo consenso de que a questão central não diz respeito somente à análise do papel do Estado, mas dos interesses sobre os corpos dessas mulheres e seus descendentes. Aqui o debate sobre a maternidade e o uso de drogas sobrepõe as discussões acerca da maternidade no contexto da rua.

Garcia 33 ao problematizar a tensão entre as garantias individuais e o papel do Estado, chama atenção para a existência de questões que são objetos de controvérsia na literatura científica. Para a autora, ainda não está claro se o uso de drogas, que essas mulheres fazem, é uma questão médica ou de segurança pública. E se essas gestantes devem ser consideradas criminosas em função desse uso de drogas e dos danos potenciais causados ao feto. Segundo a autora, se a gestação dessas mulheres for considerada um problema social cabe definir ainda em que momento o Estado deve intervir para garantir direitos de quem e quais.

"[O debate sobre] a toxicodependência durante a gravidez levanta a questão de em que momento da gestação o Estado tem interesse suficiente para justificar uma intervenção. No entanto, a questão adicional de saber se os nascituros têm o direito de nascer saudáveis agrava o problema de determinar quando o Estado deve intervir para proteger a saúde dos nascituros" 33 (p. 136).

Para Garcia 33, há uma tendência, em escala global, à criação de dispositivos jurídicos que classifiquem o uso de drogas durante o pré-natal como evidência de negligência e/ou de maus tratos infantis. Esses dispositivos estão ancorados em racionalidades que justapõem os direitos das mulheres aos fetais/infantis, e centrados nesta cisão secundarizam a "necessidade de ajuda" a essas mulheres e majoram os direitos fetais/infantis, cuja garantia só se torna possível, nesta lógica, por meio da custódia do bebê.

Para Olsen ${ }^{34}$, o padrão de resposta do Estado centrado em normativas punitivas às questões de saúde, como o uso de drogas durante a gravidez, esvazia o debate sobre questões que atravessam a produção dessas maternidades: "se nosso objetivo é evitar danos às crianças, nosso foco principal deve ser apoiar e não obrigar as mulheres e suas famílias a aderirem aos tratamentos oferecidos pelos serviços sociais" 34 (p. 29). O autor sugere que as leis que fundamentam a criminalização das maternidades dessas mulheres operam a partir da cisão entre o corpo da mulher/mãe/usuária de drogas, entendido como autora do delito e o corpo do filho compreendido como vítima do uso.

Para Maher \& Curits 35, essa forma de construir políticas produz traumas psíquicos na relação mãe/bebê e eleva os custos dos serviços sociais (instituições acolhedoras). Ao focar no controle do 
dano, as respostas do Estado desviam a atenção da compreensão de como a estrutura de classe, raça e gênero opera sobre os corpos dessas mulheres e acaba por secundarizar a necessidade de uma política nacional de saúde.

Cohen 36 , ao estudar a realização de testes toxicológicos durante a gestação, observou que as mulheres eram testadas sem seu o consentimento e sem o conhecimento dos desdobramentos da testagem, com relatos de que caso as mulheres não renunciassem a confidencialidade das relações profissionais de saúde e paciente, os bebês ao nascerem seriam retirados delas e postos em adoção. Para a autora 36 , a ideia de que essas mulheres são perigosas aos seus bebês está ancorada na crença de que o uso de drogas produz uma geração inferior, capaz de sobrecarregar os serviços de saúde, assistência social e educação. A despeito da proteção infantil, o discurso de que é preciso salvaguardar as crianças torna mais aceitável a implementação de normas centradas na punição, que além de se imporem como violação institucional de direitos, servem como justificativa para a suspensão de quaisquer direitos femininos 36 . A autora considera que tais estratégias produzem rupturas e desconfianças nos vínculos entre profissionais e mulheres.

Esses imbricamentos entre saberes/práticas biomédicas e jurídicas se expressam nos dispositivos normativos. Cohen 36 observa que a negação da autonomia das mulheres sobre o seu corpo, ainda que estas estejam grávidas, e a realização de testagem toxicológica sem o consentimento e o conhecimento dos desdobramentos, além de misógina, caracteriza negligência médica devendo estes serem responsabilizados.

Poland et al. 37 com base no relato das mulheres, discutem que as leis centradas em punição funcionariam para elas como impedimento para a utilização dos serviços de saúde e assistência social durante o pré-natal. Assim, as mulheres apresentariam mais probabilidade de não aderir aos cuidados "por medo de serem encarceradas e de perderem seus filhos" 37 (p. 202). Com isso, desmontam a crença difundida de que punir o uso de drogas por mulheres durante a gestação contribui para a abstinência.

\section{Os sentidos sobre a maternidade}

O debate sobre a maternidade como possibilidade de outros sentidos para as mulheres em situação de rua aparece em 5 dos 21 estudos. Desses, três foram publicados no Brasil 39,40,41 e dois no contexto internacional 42,43 . Há nesses estudos um núcleo de sentidos comum que considera a possibilidade de outros modos de caminhar pela vida a partir da vivência/experiência da maternidade.

Nesses estudos 39,40,41,42,43, a maternidade, desde que desejada, representaria um momento de inflexão na vida dessas mulheres, podendo ser o disparador para a construção de outros projetos de vida que tenham a saída das ruas e a interrupção do uso de drogas como metas a serem alcançadas. Contudo, autores como Costa et al. 39 e King et al. 43 reconhecem que a luta cotidiana dessas mulheres para garantir a sobrevivência se torna um entrave para que elas consigam deslocar as intenções, do campo dos desejos, para o planejamento de estratégias efetivas.

Oliveira 40 também aponta que, se por um lado, o desejo de maternar pode favorecer a construção de outros sentidos e projetos de vida, ele por si só não garante sustentabilidade aos projetos em longo prazo, pois pesam sobre essas mulheres as desigualdades geracionais.

Oliveira 40 tem utilizado o conceito de "mãe de rua" para se referir às mulheres/mães que a despeito do desejo e do cuidado com seus filhos vivem um contexto de profunda desproteção social. A "mãe de rua" é uma metáfora que expressa as contradições sociais de gênero 9 , pois é socialmente esperado que essas mulheres em nome da "prole" interrompam o uso de drogas e se tornem domiciliadas, assumindo a provisão do bem-estar social com seus filhos sem que as condições estruturais, como políticas habitacionais, favoreçam. Oliveira 40 considera que ao recair sobre as mulheres/mães de rua a responsabilidade pela provisão do bem-estar social dos filhos quase sempre o papel do pai é apagado.

No contexto internacional, King et al. 43 ao analisarem as práticas discursivas dessas mulheres, concluíram que essas maternidades podem representar um "ponto de virada na vida", desde que as condições políticas-sociais e não apenas os estilos de vida favoreçam. As autoras sugerem ainda que a chegada de um filho pode representar para elas a possibilidade de se projetar no futuro. As mulheres participantes da pesquisa referiram que "...cortar contato com os amigos e não ficar mais no centro da cidade, como parte importante do assumir um papel de mãe” 43 (p. 145). 
Resultado semelhante apresentam Almeida \& Quadros 41 ao demonstrar que havia por parte das mulheres entrevistadas certa percepção de que o contexto da rua e o uso de drogas não favorecem o desenvolvimento físico, social e psicológico de seus filhos.

Ressalte-se que a trajetória de vida dessas mulheres é marcada por experiências de violências, perdas prematuras, práticas de sexo desprotegido, questões relativas à saúde mental e dificuldades de acesso a métodos contraceptivos. Para Almeida \& Quadros 41 essas vivências atravessam as formas de exercício dessas maternidades que se distanciam do "padrão-ouro" encontrado na literatura e reconhecido como ideal.

O estudo de McClelland \& Newell 42 considera que o uso de drogas não necessariamente é preditor de uma maternidade negligente, irresponsável e relapsa, apesar de também reconhecerem que ele pode favorecer a ocorrência de comportamentos que exponham as crianças a riscos desnecessários. Vale ressaltar que a literatura tem relatado casos de mulheres/mães que tendem a orientar a escolha da droga e o desenvolvimento de estratégias para que o consumo não represente danos aos seus filhos.

"Maria dos Anjos informou (...) não fazer uso de álcool e cigarros (...) afirmando que esses hábitos não são bons para seus filhos. Elege as drogas que consome com a condição de que não perca a consciência, já que (...) seu maior pavor é que algo aconteça às crianças e que não possa estar em condições de cuidar deles...” 41 (p. 231).

Ao analisar a história de vida de três mulheres, Almeida \& Quadros 41 apontaram que por desejarem o melhor para seus filhos elas a todo o momento negociam o exercício de suas funções maternas "da maneira como podem" 41 (p. 235). Segundo as autoras, essas mães desejam para seus filhos "destinos/ futuros" diferentes dos seus. O estudo mostra que mesmo à margem e exercitando outras formas de demonstrar afeto, carinho, proteção e cuidado, as mulheres participantes da pesquisa "...transbordam sentimentos que configuram outro devir mulher-mãe" 41 (p. 236).

No que se refere ainda à maternidade como possibilidade de construção de outros projetos de vida, o estudo realizado por Costa et al. 39 sugere que algumas mulheres/mães em situação de rua não desejavam a gravidez, porém, não relatavam uso de preservativo, fato que segundo as autoras indica que as mulheres assumiam a gravidez como uma possibilidade cotidiana. Segundo o estudo ${ }^{39}$, ao descobrirem a gravidez muitas mulheres relataram insatisfação, contudo, no decorrer foram ficando felizes. As autoras 39 chamam atenção para o fato de que aceitar a gravidez não significa estabelecer com ela laços afetivos, ou desejos de ficar com a criança e materná-la.

"Constata-se um vínculo protetor, com diferentes variações: algumas buscam instituições e pessoas que possam criar seu filho com melhores condições; outras dizem que independente de sua situação atual, desejam ficar com seu filho e criá-lo; outras ainda não demonstram vínculo, o que leva ao abandono da criança” 39 (p. 1097).

A constatação de diferentes possibilidades de exercício do papel materno entre essas mulheres sugere a existência de uma percepção de que o contexto de rua com a trajetória de uso de drogas não favorece o cuidado a uma criança. Sugere ainda que, ao decidir pela "entrega" para uma instituição ou alguém próximo, com quem muitas vezes consiga manter alguma vinculação com seus filhos, essas mulheres o fazem não por não amá-los, mas justamente por acreditar que estão fazendo o melhor para eles.

\section{Considerações finais}

A análise sobre a produção discursiva da ciência a respeito das experiências de maternidade de mulheres em situação de rua possibilitou o reconhecimento das contradições, apagamentos e questões que mobilizam a ascensão do tema. Com base na identificação dos núcleos de sentidos presentes nos textos foi possível analisar como os diferentes saberes - biomédico, jurídico e socioantropológico - produzem discursos científicos e ofertam modos distintos, mas também complementares de olhar para o tema, constituindo um córpus discursivo que muitas vezes torna o discurso de proteção e cuidado ao feto/bebê hegemônico, mas também sinaliza, ainda que de modo marginal, as implicações das desigualdades sociais e os desafios a serem enfrentados para a garantia do direito à maternidade entre as mulheres em situação de rua.

Os estudos reconhecem essas gestações como uma questão de Estado e consideram que há uma centralidade em torno da ideia de proteção ao feto/criança que secundariza o entendimento do contexto de vida dessas mulheres e de suas gestações. A maioria dos estudos passa longe do debate sobre 
machismo, racismo e pobreza, acionando por vezes raça, gênero e pobreza como variáveis descritivas, esvaziando a dimensão sociológica destes conceitos e a capacidade para colocar em discussão as relações de poder como chaves que ajudam na compreensão da trajetória de vida dessas mulheres e de suas maternidades.

Apesar desse vazio, que não é ao acaso e nem mesmo uma mera coincidência, alguns estudos ressaltam a linha abissal que opera sobre os corpos das mulheres selecionando aquelas que são "autorizadas (e desejável)" a se reproduzir e aquelas que colocadas em esquemas de vigilância constante serão controladas e, até mesmo impedidas de gerar descendentes, comumente mulheres em situação de rua/ favelada e, ou usuárias de substâncias psicoativas, pretas e pobres.

Ocorre que quando uma mulher em situação de rua e, ou usuária de drogas transgride a lei e a norma, a destituição do seu poder familiar se impõe, justificada por um conjunto de enunciados ancorados na ideia de riscos ao bebê, aqui abordados especificamente nos estudos do eixo "Riscos à saúde da mulher e do feto/criança”. O discurso de risco é acionado para justificar intervenções sobre os corpos dessas mulheres, e também fundamentar a opção do Estado em sua forma jurídica e assistencial, pelo advocacy em defesa do mais vulnerável. Assim, a hegemonia do discurso biomédico do risco esconde que a separação dessas mulheres de seus filhos é contingência da condição de pobreza e da fragilidade da rede social, comunitária e familiar delas.

Ressalte-se que este debate recai sobre os riscos biomédicos, sobretudo, biológico. É a percepção desse risco que torna possível a inscrição desses corpos no domínio da política, deslocando a gestação dessas mulheres de uma questão da esfera familiar/privada para um problema de Estado, que em última análise arbitra de quem e quais direitos devem prevalecer: os da mulher em situação de rua ou os do feto/criança.

O discurso biomédico sobre o risco ao privilegiar a perspectiva biológica desloca as soluções dos problemas vivenciados por essas mulheres e seus bebês de estratégias coletivas, como políticas de redução das desigualdades (gênero, raça, pobreza, habitação, alimentação etc.), para estratégias individualizantes como abstinência, procedimentos médicos, exames laboratoriais e suspensão do poder familiar.

Destaca-se que no enunciado do risco a associação com as drogas se mostrou constante mesmo sem o uso deste termo - drogas - na estratégia de busca. Esse é mais um aspecto que reforça a ideia, não apenas caricata como equivocada, que discrimina, exclui e associa pessoas em situação de rua ao consumo de drogas.

Um contraponto ao enunciado do risco apresenta-se no discurso sobre o pré-natal, embora tenham sido localizados apenas dois estudos. Tanto no âmbito nacional como no internacional verificou-se estratégias de aproximação e reconhecimento das especificidades que envolvem o cuidado pré-natal a essas mulheres, bem como as barreiras que se impõem por questões estruturais. Os estudos reconhecem que há riscos na maternidade de mulheres em situação rua, mas que o pré-natal pode ser colocado como uma tecnologia de cuidado capaz de reduzir riscos, numa aposta na organização de um cuidado intersetorial, territorializado, humanizado, operado por tecnologias leves e leve-dura. Ainda assim, ressaltam que um pré-natal realizado (ou não) em tempo oportuno e protocolar não é necessariamente indicador da capacidade futura de maternagem dessas mulheres.

A literatura examinada apontou que as soluções para as tensões entre os direitos das mulheres e os do feto/criança implica a coerção/punição e a oferta (obrigatória) de assistência com foco no bem-estar infantil. Santos et al. ${ }^{9}$, em trabalho recente, chamam atenção para o fato de que mesmo em serviços de saúde do SUS, orientado por valores altruístas e humanitários, mulheres em situação de rua usuárias de drogas são estigmatizadas e culpabilizadas por sua condição de pobreza e de uso de drogas. Os autores indicam que ainda impera na organização dos serviços o ideal da mulher dona de casa, boa esposa e mãe virtuosa.

Nesse contexto, as ações assistenciais, a despeito do cuidado ao feto/criança ou mesmo à mulher, por mais bem intencionadas que possam ser, não estão isentas de criar outras situações de violência além daquelas já presentes no contexto de rua e na trajetória de vida dessas mulheres 3 . A contradição dessas práticas seria a produção da "perversidade do 'ato do bem"” 19 em que a cidadania esbarra nos limites das leis.

Na esteira dessas contradições há uma importante contribuição dos estudos na denúncia das graves violações que sofrem essas mulheres e a necessidade de pautar limites às ações do Estado, inclusive 
para que este não cometa excessos em sua intervenção. Os trabalhos revelam que a criminalização dessas maternidades tem sido uma tendência global em que a expansão dos direitos "fetais/infantis" significa a retração dos direitos das mulheres, o que faz com que elas não busquem os serviços sociais e de saúde.

Assim, “De quem é esse bebê?”, pergunta que dá título a este artigo, não é uma questão simples e sua resposta, via de regra, exige uma complexa atividade de articulação entre as dimensões da vida humana que estão profundamente interligadas, desde os processos macropolíticos que mantêm a reprodução das condições estruturais que atravessam os modos de vida na rua, como, por exemplo, a pobreza, o racismo e o patriarcado, até os processos subjetivos que dizem respeito ao sentido da maternidade e da rua na vidas dessas mulheres. Torna-se um imperativo ético e humanitário pensar outros modos de cuidar, ancorados na perspectiva dos direitos humanos, para que a assistência ao feto/criança não se traduza em violência às mulheres.

\section{Colaboradores}

G. C. Santos realizou a concepção do estudo e a redação do artigo. T. W. F. Baptista e P. Constantino revisaram o artigo. Todos os autores aprovaram a versão final.

\section{Informações adicionais}

ORCID: Gilney Costa Santos (0000-0002-06737869); Tatiana Wargas de Faria Baptista (00000002-3445-2027); Patrícia Constantino (00000001-5835-0466).

\section{Agradecimentos}

Os autores agradecem ao Conselho Nacional de Desenvolvimento Científico e Tecnológico (CNPq), ao Programa de Excelência Acadêmica/Coordenação de Aperfeiçoamento de Pessoal de Nível Superior (Proex/CAPES) e ao Programa Bolsa Nota 10 da Fundação Carlos Chagas Filho de Amparo à Pesquisa do Estado do Rio de Janeiro (FAPERJ), pelo financiamento da bolsa de Doutorado em Saúde Pública possibilitando a realização do estudo. 


\section{Referências}

1. Vosgerau D, Romanowski J. Estudos de revisão: implicações conceituais e metodológicas. Revista Diálogo Educacional 2014; 14:165-89.

2. Butler J. Problemas de gênero: feminismo e subversão da identidade. Rio de Janeiro: Civilização Brasileira; 2013.

3. Lima MS. A quem pertence essa gravidez? Reflexões sobre a maternidade/maternagem de mulheres que fazem uso de drogas e as agentes do estado [Dissertação de Mestrado]. Rio de Janeiro: Universidade do Estado do Rio de Janeiro; 2018.

4. Boyd S. Mulheres, drogas e o rapto de seus filhos. In: Mendes N, Merhy E, Silveira P, organizadores. Extermínio dos excluídos. Porto Alegre: Rede Unida; 2019. p. 214-25.

5. Mulheres viciadas em crack usam droga durante gestação e colocam bebês em risco. Fantástico; 2012. Vídeo: 15:19 min. https://globo play.globo.com/v/2213203/.

6. Lancetti A. Contrafissura e plasticidade psíquica. São Paulo: Editora Hucitec; 2015.

7. Silveira $\mathrm{P}$, Alexander, BK. A "guerra às drogas" terá fim? Por quê? In: Mendes N, Merhy E, Silveira $\mathrm{P}$, organizadores. Extermínio dos excluídos. Porto Alegre: Rede Unida; 2019. p. 16085.

8. Rodrigues T. Tráfico, guerra, proibição. In: Labate BC, Goulart S, Fiore M, MacRae E, Carneiro $\mathrm{H}$, organizadores. Drogas e cultura: novas perspectivas. Salvador: EdUFBA; 2008. p. 91-104.

9. Santos GC, Constantino P, Schenker M, Rodrigues LB. O consumo de crack por mulheres: uma análise sobre os sentidos construídos por profissionais de consultórios na rua da cidade do Rio de Janeiro, Brasil. Ciênc Saúde Colet 2020; 25:3795-808.

10. Brasil. Decreto no 7.179 , de 20 de maio de 2010. Institui o Plano Integrado de Enfrentamento ao Crack e outras Drogas, cria o seu Comitê Gestor, e dá outras providências. Diário Oficial da União 2010; 21 mai.

11. Santos MPG. Comunidades terapêuticas: temas para reflexão. Rio de Janeiro: Instituto de Pesquisa Econômica Aplicada; 2018.

12. Ministério Público do Estado de Minas Gerais. Recomendação no 05/2014. https://dequeme estebebe.files.wordpress.com/2017/04/reco mendaccca7acc83o-5_2014mp.pdf (acessado em 31/Ago/2020).

13. Ministério Público do Estado de Minas Gerais. Recomendação no 06/2014. https://dequeme estebebe.files.wordpress.com/2017/04/reco mendaccca7acc83o-6_2014mp-1.pdf (acessado em 31/Ago/2020).
14. Vara da Infância e da Juventude de Belo Horizonte. Portaria no 3/VCIJBH/2016. Dispõe sobre o procedimento para encaminhamento de crianças recém-nascidas e dos genitores ao Juízo da Infância e da Juventude, assim como oitiva destes, nos casos de grave suspeita de situação de risco, e sobre o procedimento para aplicação de medidas de proteção. Diário de Justiça do Estado de Minas Gerais 2016; 22 jul.

15. Em BH, mães com histórico de uso de drogas têm seus bebês retirados na maternidade. Jornal GGN 2017; 20 jul. https://jornalggn.com. br/direitos-humanos/em-bh-maes-com-histo rico-de-uso-de-drogas-tem-seus-bebes-reti rados-na-maternidade/.

16. Maricato G, Sousa ACM. Sequestro e negligência como política de Estado: experiências da segunda geração de atingidos pela hanseníase. Saúde Redes 2018; 4 Suppl 1:153-68.

17. Associação Brasileira da Rede Unida. Saúde Redes 2018; 4 Suppl 1:5-252.

18. Ministério da Saúde; Ministério do Desenvolvimento Social e Combate à Fome. Nota Técnica Conjunta no 001/2016. http:// www.mpgo.mp.br/portal/arquivos/2016/ $10 / 31 / 18 \_21 \_17 \_558 \_$Nota_T\%C 3\% A9cnica_Conjunta_MDS_e_MS_FINAL_1. pdf (accessed on 28/Apr/2021).

19. Ferla AA, Jorge A, Merhy E. Separação compulsória de mães e seus filhos: quando a lei e a cidadania se confrontam. Saúde Redes 2018; 4 Suppl 1:5-8.

20. Spink MJ. Práticas discursivas e produção de sentidos no cotidiano: aproximações teóricas e metodológicas. São Paulo: Cortez Editora; 2004.

21. Badinter E. Um amor conquistado: o mito do amor materno. Rio de Janeiro: Nova Fronteira; 1985.

22. Kassada DS, Marcon SS, Pagliarini MA, Rossi M. Prevalência do uso de drogas de abuso por gestantes. Acta Paul Enferm 2013; 26:467-71.

23. Sakamoto LC, Malavasi A, Karasinb AL, Frajzinger RC, Araújo MR, Gebrim LH. Prevenção de gestações não planejadas com implante subdérmico em mulheres da Cracolândia, São Paulo. Reprod Clim 2015; 30:102-7.

24. Rocha PC, Alves MTSSB, Chagas DC, Silva AAM, Batista RFL, Silva RA. Prevalência e fatores associados ao uso de drogas ilícitas em gestantes da coorte BRISA. Cad Saúde Pública 2016; 32:e00192714.

25. Gustavsson NS. Drug exposed infants and their mothers: facts, myths, and needs. Soc Work Health Care 1992; 16:87-100. 
26. Bassuk EL, Weinreb L. Homeless pregnant women: two generations at risk. Am J Orthopsychiatry 1993; 63:348-57.

27. Bloom KC, Bednarzyk MS, Devitt D, Renault RA, Teaman V, Loock MV. Barriers to prenatal care for homeless pregnant women. J Obstet Gynecol Neonatal Nurs 2004; 33:428-35.

28. Schempf AH, Strobino DM. Illicit drug use and adverse birth outcomes: is it drugs or context? J Urban Health 2008; 85:858-73.

29. Leppo A. "Subutex is safe": perceptions of risk in using illicit drugs durin pregnancy. Int J Drug Policy 2012; 23:365-73.

30. Castiel LD, Guilam MCR, Ferreira MS. Correndo o risco: uma introdução aos riscos em saúde. Rio de Janeiro: Editora Fiocruz; 2015.

31. Araújo MAS, Santos AAP, Lúcio IML, Tavares CM, Fidélis EPB. O contexto da gestante na situação de rua e vulnerabilidade: seu olhar sobre o pré-natal. Rev Enferm UFPE On Line 2017; 11 Suppl 10:4103-10.

32. Beal AC, Redlener I. Enhancing perinatal outcome in homeless women: the challenge of providing comprehensive healt care. Semin Perinatol 1995; 19:307-13.

33. Garcia SA. Drug addiction and mother/child welfare. J Leg Med 1992; 13:129-203.

34. Olsen A. Punishing parents: child removal in the context of drug use. Drug Alcohol Rev 2014; 34:27-30.

35. Maher L, Curtis R. Women on the edge of crime: crack cocaine and the changing contexts of street-level sex work in New York City. Crime Law Soc Change 1992; 18:221-58.
36. Cohen LB. Informing consent: medical malpractice and the criminalization of pregnancy. Mich Law Rev 2018; 116:1297-316.

37. Poland ML, Dombrowskia MP, Agerb WJ, Sokol RJ. Punishing preganant drug users: enhancing the flight from care. Drug Alcohol Depend 1993; 31:199-203.

38. Moss KL. Substance dependency durin pregnancy: the limits of the law. Womens Health Issues 1991; 1:120-6.

39. Costa SL, Vida CPC, Gama IA, Locatelli NT, Karam BJ. Gestantes em situação de rua no Município de Santos - SP: reflexões e desafios para as políticas públicas. Saúde Soc 2015; 24:1089-102.

40. Oliveira ES. "Por sua culpa, sua tão grande culpa": um estudo sobre o processo de naturalização, responsabilização e culpabilização das mães dos meninos e meninas em situação de rua [Tese de Doutorado]. São Paulo: Pontifícia Universidade Católica de São Paulo; 2015.

41. Almeida DJR, Quadros LCT. A pedra que pariu: narrativas e práticas de aproximação de gestantes em situação de rua e usuárias de crack na cidade do Rio de Janeiro. Pesqui Prát Psicossociais 2016; 11:225-37.

42. McClelland GT, Newell R. A qualitative study of the experiences of mothers involved in street-based prostitution and problematic substance use. J Res Nurs 2008; 13:437-47.

43. King KE, Ross LE, Bruno TL, Erickson PG. Identity work among street-involved young mothers. J Youth Stud 2009; 12:139-49. 
Abstract

The experiences of homeless pregnant women create tensions in the public debate between individual guarantees and limits on State interventions. This article analyzes the scientific research on this issue, focusing on the biomedical, legal, and social arguments backing the positions in this debate. Based on an integrative review of Brazilian and international databases, the authors analyzed 21 studies and identified four propositions: Health risks for the woman and the fetus/child; Discourses on prenatal care; Rights of women and fetuses/ children; and Meanings of motherhood. The article concludes that the experience of motherhood for these women is extremely complex, not only because of their homelessness, but due to the entire context, marked by unequal class, race, and gender relations. The Brazilian and international scenario features a discourse of protection and care for the fetus/infant that overrides care for the mother. The criminalization of homeless women's motherhood has been a global trend in which the expansion of "fetal/infant" rights translates as a cutback in the women's rights. Such an approach fails to encourage homeless women to seek social and health services, rather discouraging them from doing so. An ethical and humanitarian imperative is to conceive different approaches to care, grounded in a human rights perspective so that care for the fetus/child does not translate as violence against the mother.

Women; Gender; Parenting; Homeless Persons; Human Rights

\section{Resumen}

Las experiencias de mujeres gestantes sin techo exponen a debate público tensiones entre las garantías individuales y los límites a las acciones del Estado. Este artículo analiza la producción científica sobre el tema, a fin de reconocer los argumentos biomédicos, jurídicos y sociales que sostienen los posicionamientos en este debate. A partir de una revisión integral, en bases de datos con alcance brasileño e internacional, se analizaron 21 estudios, donde se identificaron cuatro enunciados: Riesgos para la salud de la mujer y del feto/bebé; Discursos sobre el período prenatal; Derechos de mujeres y de fetos/bebés; $y$ Los sentidos sobre maternidad. Se concluye que la experiencia de maternidad de esas mujeres es extremadamente compleja, no solamente por la situación sin techo, sino por todo el contexto, marcado por relaciones desiguales de clase, raza y género. En el escenario brasileño e internacional, sobresale el discurso de protección y cuidado al bebé/feto, en detrimento de las mujeres gestantes. La criminalización de esas maternidades ha sido una tendencia global, donde la expansión de los derechos "fetales/infantiles" significa la retracción de los derechos de las mujeres. Este modo de actuar no consigue y no incentiva que las mujeres busquen servicios sociales y de salud, sino todo lo contrario. Se convierte en un imperativo ético y humanitario pensar en otros modos de tratar esta cuestión, desde una perspectiva de derechos humanos, para que la asistencia al feto/bebé no se traduzca en violencia hacia las mujeres.

Mujeres; Género; Maternidad; Personas sin

Hogar; Derechos Humanos
Recebido em 16/Set/2020

Versão final reapresentada em 29/Jan/2021

Aprovado em 06/Fev/2021 